\title{
The effect of lameness on the fertility of dairy cattle in a seasonally breeding pasture-based system
}

\author{
J. I. Alawneh, R. A. Laven, ${ }^{1}$ and M. A. Stevenson \\ Institute of Veterinary, Animal and Biomedical Sciences, Massey University, Palmerston North, NZ 4471
}

\begin{abstract}
The effect of lameness on the fertility of dairy cattle is well recognized. But, the effect of lameness on the fertility of seasonally breeding cattle in pasture-based systems is less well characterized. This prospective cohort study of 463 cows on 1 farm in the lower North Island of New Zealand was designed to assess the effect of clinical lameness, as identified by farm staff, on the hazard of conception after the planned start-ofmating date. A Cox proportional hazards model with time-varying covariates was used. After controlling for the effect of parity, breed, body weight at calving, and calving-to-planned start of mating interval, the daily hazard of conception for cows identified as lame was 0.78 (95\% confidence interval: 0.68-0.86) compared with non-lame cows. Lame cows took $12 \mathrm{~d}$ longer to get pregnant compared with their non-lame counterparts.
\end{abstract}

Key words: lameness, fertility, seasonal breeding, survival analysis

\section{INTRODUCTION}

Lameness is one of the most important diseases of the dairy cow. It causes significant long-lasting pain, even after treatment (Whay et al., 2005; Laven et al., 2008), and has a major economic effect (Ettema et al., 2010).

One of the key mechanisms by which lameness decreases productivity is its effect on reproduction. Lameness affects fertility at all stages of the reproductive cycle. Lame cows resume normal postpartum activity more slowly than their non-lame cohorts. Garbarino et al. (2004) showed that lame cows had 3.5 times greater odds of not resuming cyclicity within $60 \mathrm{~d}$ of calving compared to non-lame cows, and that preventing lameness would have decreased the number of cows with delayed cyclicity by $71 \%$. This delay in cyclicity means that lame cattle likely require treatment for anestrus (Hultgren et al., 2004). Even when ovarian activity has resumed, lame cows have compromised estrous behavior. Walker et al. (2008) reported that lame cows were

Received March 27, 2011.

Accepted July 1, 2011

${ }^{1}$ Corresponding author: r.laven@massey.ac.nz mounted less frequently, expressed estrus with lower intensity, and had decreased conception rates (Hernandez et al., 2001; Melendez et al., 2003; Bahonar et al., 2009).

The majority of research on the effect of lameness on fertility has focused on non-seasonal systems. Extrapolation of such data to seasonal systems may not be valid, as the differences between the systems could affect the relationship between fertility and lameness. In seasonal pasture-based systems, such as those which predominate in New Zealand, to achieve calving intervals of $<380 \mathrm{~d}$, calving-to-first service intervals must be relatively short compared with cows in non-seasonally calving dairy herds. In addition, anestrous cattle are induced to ovulate at the start of the breeding period (McDougall, 2010). Finally, the management of lame cows is different. In New Zealand, lame cows are routinely separated from the main herd and milked once daily. This management routine, combined with pasture rather than housing lame cows, may decrease the severity of lameness (Hernandez-Mendo et al., 2007; Laven et al., 2008) and influence the effect of lameness on fertility. Only limited, mostly anecdotal, information is available concerning the effect of lameness in seasonal systems. Tranter and Morris (1991) showed that the percentage of lame cows that were pregnant within 6 wk of the start of the breeding season was lower than that of non-lame cows (41 vs. $62 \%$, respectively), but this did not take into account other factors that influence fertility, such as the interval between calving and the start of the mating period, age, and BW (Rhodes et al., 1998b; Clark et al., 2000; Thiengtham et al., 2008). More data on the relationship between reproduction and lameness in seasonal pasture-based systems are required. The objective was to assess the incidence risk and the effect of clinical lameness, as identified by farm staff, on the daily hazard of conception after the planned start of mating (PSM) in a seasonally bred and traditionally managed pasture-based herd in New Zealand.

\section{MATERIALS AND METHODS}

This was a prospective observational study of mixed age $(\mathrm{n}=463)$ and breed (226 Holstein-Friesian, 5 
Jersey, and 232 Holstein-Friesian $\times$ Jersey crossbred) dairy cows that calved between July 15 and October 24, 2008 and were present at the PSM (October 24, 2008) in a single dairy herd in Palmerston North in the lower North Island of New Zealand. Cows grazed as a single group and had free access to water. The herd was managed so that the pasture allowance and access to supplementation after the morning milking (palm kernel meal to a maximum of $2 \mathrm{~kg}$ of $\mathrm{DM} / \mathrm{cow}$ per day and corn silage to a maximum of $2 \mathrm{~kg}$ of DM/cow per day) was sufficient for maintenance and production requirements of a 400-kg cow producing $2.0 \mathrm{~kg}$ of milk solids/d. Cows were milked twice daily, starting at 0530 and $1500 \mathrm{~h}$ through a 50-stall rotary-platform milking parlor (DeLaval Parallel Rotary; DeLaval International AB, Tumba, Sweden). Walkover BW was recorded for each cow from when it entered the milking herd after calving. The BW for each cow was measured using an automatic walkover weighing system using a calibrated electronic walkover scale system (WOW! XR-3000; Tru-Test Ltd., Auckland, New Zealand).

\section{Reproductive Management}

Pre-mating estrous events were recorded by farm staff 1 mo before the PSM. From the PSM until December 6, 2008, cows went through AI by a contract inseminator who visited the farm once daily. For the 7 -wk period from December 7, 2008 to January 25, 2009, 8 bulls were placed with the milking herd. One bull was put in with the problem group of the herd, which included all lame cows and those with other problems such as mastitis.

Detection of estrus was conducted by farm staff using direct observation and tail paint [FIL oil-based tail paints, fluorescent estrous detection tail paint, Tell Tail (FIL, Mount Maunganui, New Zealand)]. Cows were observed by staff in the field for 30 to 45 min before each milking, while they traveled from the pasture to the milking parlor, and throughout each milking ( $3 \mathrm{~h}$ for each milking; Alawneh et al., 2006). A cow was considered in estrus if more than $50 \%$ of her tail paint was removed or she showed typical behaviors of estrus (standing to be mounted, mounting other cows, and head mounting).

Pregnancy was diagnosed by ultrasound examination 5 and 13 wk after the end of the 12 -wk mating period to identify the service (based on farm records and fetal aging) that resulted in conception.

\section{Lameness Management and Recording}

Clinical lameness cases were identified and managed according to farm practice. At the start of the study, the farm manager received detailed instructions (Chesterton et al., 2008) from the herd veterinarian to clarify issues on detection of lameness and preliminary treatment of identified cases. The farm manager then trained all staff members to ensure consistent identification and management of lame cows. The following protocol was applied: any cow that was observed by the farm staff as having a persistent gait abnormality was identified for further investigation. Cows identified as lame on examination were treated by farm staff or held for veterinary examination. All diagnoses other than foot rot were made by the second author. After treatment, which consisted of antibiotics for cows with foot rot, and trimming, for cows with claw horn lesions, lame cows were placed on a once-daily milking regimen and separated from the main herd in fields near to the milking parlor, until the farm staff considered that they had recovered when they were returned to the main milking herd.

\section{Data Management}

Dates and facts of calving, estrus, service, disease and treatment events, reproductive examinations, dry-off, and culling events were recorded into paper records kept at the milking shack. At regular intervals, these details were transferred to a computerized herd management software package [DairyWIN 2004 v99.91.148 (http:// www.dairywin.co.nz); Massey University, Palmerston North, New Zealand]. The BW data were downloaded from the scale system twice weekly (Monday and Thursday) after the morning milking and transferred to the herd health management program.

Data evaluation procedures were conducted before analysis. Service events within $3 \mathrm{~d}$ of each other were treated as a single service. A lameness event identified within $14 \mathrm{~d}$ (Dohoo and Martin, 1984) of a prior lameness diagnosis was considered the same event, unless it occurred in another foot. Erroneous BW records were identified and removed from the data set. Daily BW records were averaged to a single daily measurement. Individual cow BW at calving were quantified by averaging daily BW measurements during the first $7 \mathrm{~d}$ after parturition (Schwager-Suter et al., 2001).

The data set was arranged so that each DIM was regarded as a single observation. Each observation comprised details of the identity of the cow, the start and end date for the observation, whether or not the outcome of interest occurred ( 1 if the cow conceived and 0 if nonpregnant), and the values of each of the measured explanatory variables: (1) parity as a categorical variable with 2 levels (first parity and cows $>$ first parity); (2) breed as a categorical variable with 2 levels (Holstein-Friesian and crossbred cows; Jerseys 
were combined with crossbreds); (3) BW at calving as a continuous variable; and (4) calving-to-PSM interval, expressed in days.

\section{Statistical Analyses}

The first analysis quantified the incidence risk and rate of lameness from calving to the end of lactation. The incidence risk of lameness was defined as the total number of cows experiencing at least 1 lameness event from calving to the end of lactation period divided by the average number of cows that were present in the herd throughout the same period (Szklo and Nieto, 2007). Kaplan-Meier survival curves were computed to calculate cow-days at risk between observed lameness events. Briefly, days at risk for each member of the herd comprised the number of days between calving and the end of lactation date or the date of removal from the herd (e.g., culling date or drying-off date). Cows identified as lame stopped contributing days at risk from the date a lameness event was diagnosed until $14 \mathrm{~d}$ after the last recorded lameness event date. After that time, cows became re-eligible to contribute time at risk. The incidence rate of lameness was defined as the total number of lameness diagnoses made divided by the total number of cow-days at risk. The instantaneous hazard of lameness was defined at calendar date $t$ as the proportion of the cows present on date $t$ that were identified as lame on date $t$ (Kleinbaum and Klein, 2005).

The second analysis investigated the variables influencing the number of days for cows to conceive after the PSM. Kaplan-Meier survival curves were used to compare the distribution of days to conception after the PSM for lame and non-lame cows and to calculate median days to conception [the $95 \%$ CI were calculated based on log (survival) for each group]. Kaplan-Meier survival curves for lame and non-lame cows were generated and the homogeneity of the curves was tested using the log rank statistic (Kleinbaum and Klein, 2005). Finally, a Cox proportional hazards model with time varying covariates (Suriyasathaporn et al., 1998; Kleinbaum and Klein, 2005; Dohoo et al., 2009) was used to identify variables influencing the number of days for cows to conceive following the PSM. In this analysis, cows that did not conceive or that were removed from the herd through the mating period were right-censored at the end of the mating period on January 25, 2009, or at removal from the herd date as described previously. Explanatory variables were screened by entering each into a bivariate Cox proportional hazards model and those with a likelihood ratio test $P$-value $\leq 0.25$ were retained for inclusion in a multivariable Cox proportional hazards model. Explanatory variables that were not statistically significant at an $\alpha$ of $\leq 0.05$ were removed from the final model one at a time, until the estimated regression coefficients for all of the variables retained were significant at a level of $P \leq 0.05$, unless they were considered either biologically important or a confounder when they were retained in the final model even if they were not significant at a level of $P$ $\leq 0.05$. A variable was considered as a confounder if it influenced other covariates estimates by $>20 \%$ (Dohoo et al., 2009). Two-way interactions were assessed and retained if they were significant at an $\alpha$ of $\leq 0.05$. The daily hazard of conception $\left[h_{i}(t)\right]$ was calculated as

$$
h_{i}(t)=h_{0}(t) \exp \left[\left(\beta_{1} \chi_{1 i}+\ldots+\beta_{m} \chi_{m i}\right)+\gamma_{1} z_{1}(t)\right],
$$

where $h_{0}(t)$ represents the baseline hazard as a function of time; $\beta_{1}, \ldots, \beta_{m}$ represent the regression coefficients for each of the $m$ time-invariant covariates (parity, breed, BW at calving, and calving-to-PSM interval); $X_{1 i}, \ldots, X_{m i}$ represent the covariates for each of the observations; $\gamma_{1}$ is the estimated regression coefficient for effect of lameness as a time varying covariate on day $(t)$; and $z_{1}$ is lameness status $(0,1)$ at day $t$.

The proportional hazards assumption of the Cox model was tested for categorical variables by examining for each stratum plots of $\log [-\log S(t)]$, where $\mathrm{S}(t)$ is the survival function for each stratum, against time with the expectation that the plots would be parallel. For continuous variables, the proportional hazard assumption was tested using a plot of the scaled Schoenfeld residuals as a function of time to event with the expectation that no association would occur between the residuals and time to event.

The scale of each continuous variable was tested using the Martingale residuals. A plot of Martingale residuals from a model that excludes the continuous variable against the values of the excluded continuous variable was examined with the assumption that the relationship would be linear (Hosmer et al., 2008). Covariate-adjusted survival curves, based on the results of the Cox proportional hazards model, were computed using the modified estimated risk score approach described by Hosmer et al. (2008). All statistical analyses were performed using $\mathrm{R}$ version 2.8.0 ( $\mathrm{R}$ Development Core Team, 2010) and the survival library (Therneau and Lumley, 2009).

\section{RESULTS}

Table 1 provides descriptive statistics of BW at calving and days open for the parity grouping used in this study. Details of the number of lameness events and the incidence risk, and incidence rate of lameness are in Table 2. The instantaneous hazard of lameness for 
Table 1. Descriptive statistics of BW at calving, calving-to-planned start of mating (PSM) interval, and PSM-to-conception interval by parity grouping

\begin{tabular}{|c|c|c|c|c|}
\hline Characteristic & $\begin{array}{c}\text { No. of } \\
\text { cows }\end{array}$ & $\begin{array}{l}\text { Mean } \\
(\mathrm{SD})\end{array}$ & $\begin{array}{c}\text { Median } \\
(\mathrm{Q} 1, \mathrm{Q} 3)^{1}\end{array}$ & $\begin{array}{l}\text { Min, } \\
\max ^{2}\end{array}$ \\
\hline First parity & 101 & & & \\
\hline Calving-to-PSM interval (d) & & $73(13)$ & $79(66,82)$ & 31,97 \\
\hline PSM-to-conception interval (d) & & $37(17)$ & $38(28,47)$ & 4,61 \\
\hline$>$ First parity & 362 & & & \\
\hline Calving-to-PSM interval (d) & & $55(16)$ & $59(41,71)$ & 13,99 \\
\hline PSM-to-conception interval (d) & & $35(19)$ & $35(22,47)$ & 1,76 \\
\hline \multicolumn{5}{|l|}{ Breed } \\
\hline Holstein-Friesian & 226 & & & \\
\hline Crossbred and Jersey & 237 & & & \\
\hline
\end{tabular}

${ }^{1} \mathrm{Q} 1=$ first quartile; $\mathrm{Q} 3=$ third quartile.

${ }^{2} \operatorname{Min}=$ minimum $; \max =$ maximum.

the interval from planned start of calving to the end of lactation is in Figure 1. The instantaneous hazard of lameness increased exponentially to 0.2 (95\% CI 0.0 $0.6)$ per 100 cow-days in the first $16 \mathrm{~d}$ after the PSM, after which time it decreased steadily until December 20, 2008 (Figure 2). A total of 802 service events were recorded throughout the mating period.

Of the 463 cows enrolled, details for 11 cows were excluded from the analysis in Table 3 on the basis of either incomplete data $(\mathrm{n}=3)$ or they were observed lame before the PSM $(\mathrm{n}=8)$. The distribution of days to conception after the PSM differed significantly between lame and non-lame cows $(P<0.01)$. The median interval from the PSM to conception was $40 \mathrm{~d}(95 \%$ CI 28-45) for lame cows compared with 28 d (95\% CI 23-33) for non-lame cows: a difference of $12 \mathrm{~d}$. The effect of lameness on the daily hazard of conception after the PSM is shown in Table 3. After controlling for the effect of parity, breed, BW at calving, and calvingto-PSM interval, the daily hazard of conception for lame cows was decreased by a factor of 0.78 (95\% CI $0.68-0.86 ; P<0.01)$ compared with cows that were not lame. Cows in greater than first parity had a higher daily hazard ratio (HR) of conception compared with first-parity cows (HR 1.11, 95\% CI 1.05-1.22), and cows that were crossbred or Jersey had a higher daily HR of conception compared with Holstein-Friesians (HR 1.34, 95\% CI 1.26-1.42), Covariate-adjusted survival curves for lame and non-lame first-parity cows are in Figure 3. The survival curve for first-parity cows that were lame indicated that $50 \%$ were pregnant by $54 \mathrm{~d}$ after the PSM, and that $20 \%$ were still open at $84 \mathrm{~d}$ after the PSM.

\section{DISCUSSION}

Sixty-eight lameness events (68 cows) occurred throughout the lactation, resulting in an estimated incidence risk of $15 \%$. This is lower than the proportion of cows reported as lame in similar studies in the United States (Garbarino et al., 2004; Hernandez et al., 2005), United Kingdom (Collick et al., 1989; Green et al., 2002), and Europe (Barkema et al., 1994), but supports Tranter and Morris (1991) and Gibbs (2010) for New Zealand cattle, so is consistent with the conclusion that lameness is less common in New Zealand than confinement systems used in the Northern Hemisphere (Laven and Holmes, 2008).

Table 2. Number of lameness cases by diagnosis, number of cows at risk, total number of cow-days at risk, and incidence risk and incidence rate (with 95\% CI) for the study animals

\begin{tabular}{lccccc}
\hline $\begin{array}{l}\text { Lameness } \\
\text { lesion }^{1}\end{array}$ & $\begin{array}{c}\text { No. } \\
\text { lame }\end{array}$ & $\begin{array}{c}\text { No. at } \\
\text { risk }\end{array}$ & $\begin{array}{c}\text { No. of } \\
\text { cow-days }\end{array}$ & $\begin{array}{c}\text { Incidence } \\
\text { risk }^{2}\end{array}$ & \begin{tabular}{c} 
Incidence $_{\text {rate }^{3}}$ \\
\hline White line
\end{tabular} \\
$\begin{array}{l}\text { Foot rot } \\
\text { Sole injury }\end{array}$ & 27 & 452 & 107,468 & $8(6-11)$ & $3.4(2.5-4.7)$ \\
Total & 4 & 452 & 110,536 & $6(4-9)$ & $2.4(1.6-3.5)$ \\
\hline
\end{tabular}

${ }^{1}$ Definitions as per Chesterton et al. (2008).

${ }^{2}$ Cases per 100 cows at risk.

${ }^{3}$ Cases per 100 cow-days at risk. 


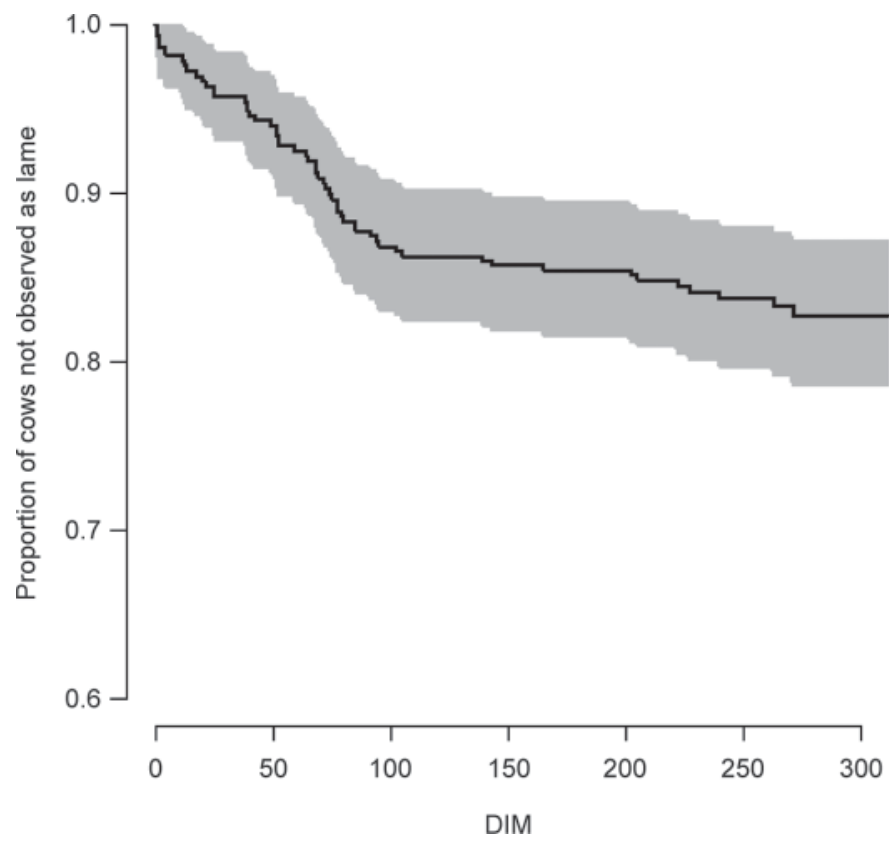

Figure 1. Kaplan-Meier survival curve (solid line) showing the cumulative proportion of cows not observed as lame as a function of DIM over the 2008 lactation. The gray shaded area represents the $95 \%$ confidence interval for the estimated curve.

Despite this lower incidence, the data from this study suggest that the effect of lameness on fertility in pasture-based systems is similar to that in housed cattle. Overall, the daily hazard of conception for lame cows was decreased by a factor of 0.78 compared with non-lame cows. In a similar cohort study in the United States, Hernandez et al. (2001) reported that cattle with claw lesions, which accounted for 41/68 lameness cases in their study, had an HR of conception of 0.52 and cattle with foot rot had an HR of 0.65. In Iran, Bahonar et al. (2009) reported an HR, for all causes of lameness, of 0.77. In Europe, Hultgren et al. (2004)

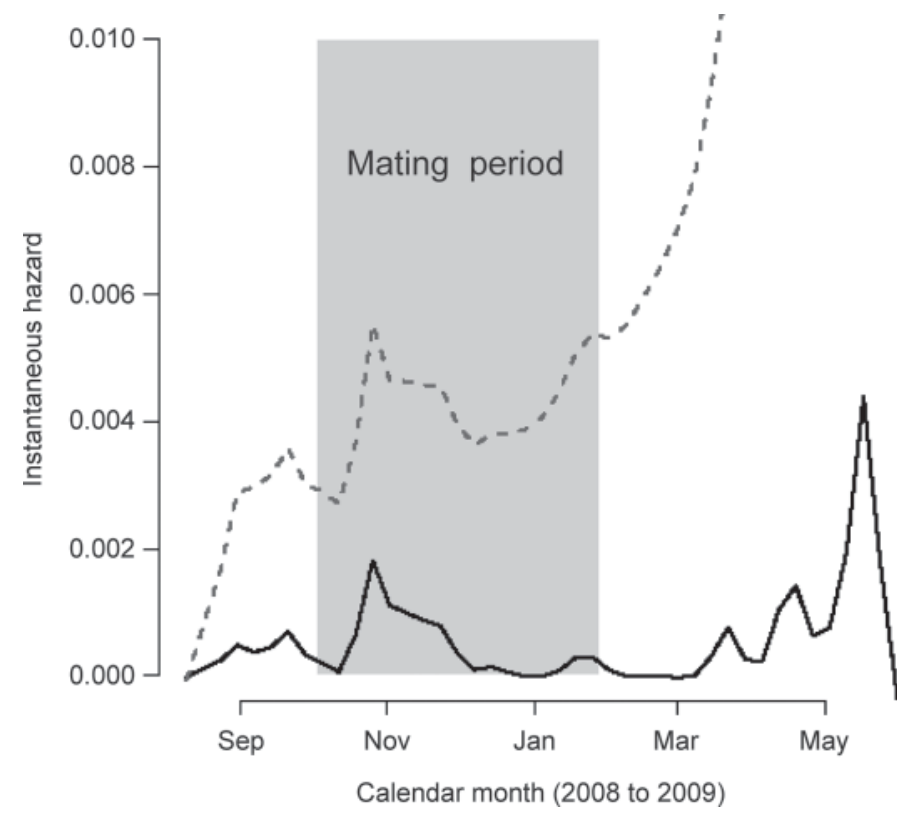

Figure 2. Daily hazard of lameness for the study animals (solid line) and upper $95 \%$ confidence interval (dashed line) from planned start of calving (July 15, 2008) to the end of lactation. The instantaneous hazard of lameness at day $t$ ( $t$ is a calendar date) was defined as the proportion of cows present on day $t$ identified lame on day $t$. The gray area marks the beginning (October 24, 2008) and end (January $25,2009)$ of the mating period. On October 27, 2008, the hazard of lameness was 0.002 . That is, $(0.002 \times 452)=1$ lame cow was identified on that day.

reported cows with sole ulcer had an odds ratio of conceiving of 0.59 compared with non-lame cows, whereas Collick et al. (1989) reported that the conception rate of inseminated lame cows was only $46 \%$ compared with $56 \%$ in non-lame cows.

The results of the current study support the conclusion of Tranter and Morris (1991) that lameness significantly decreases the fertility of seasonally bred pasture-based cattle. In the current population, the

Table 3. Multivariable Cox proportional hazards regression model for the interval from planned start of mating (PSM) to conception date using the incidence of lameness as a time-dependent covariate

\begin{tabular}{|c|c|c|c|}
\hline Variable & $\begin{array}{l}\text { Coefficient } \\
\quad(\mathrm{SE})\end{array}$ & $P$-value & $\begin{array}{c}\text { Hazard ratio } \\
(95 \% \mathrm{CI})\end{array}$ \\
\hline \multicolumn{4}{|l|}{ Parity } \\
\hline 1 & - & - & 1.00 \\
\hline$>1$ & $0.12(0.039)$ & $<0.01$ & $1.11(1.05-1.22)$ \\
\hline \multicolumn{4}{|l|}{ Breed } \\
\hline Holstein-Friesian & - & - & 1.00 \\
\hline Crossbred and Jersey & $0.29(0.030)$ & $<0.01$ & $1.34(1.26-1.42)$ \\
\hline BW (50-kg increments) ${ }^{1}$ & $0.03(0.161)$ & 0.11 & $1.03(0.74-1.41)$ \\
\hline Calving to PSM (d) & $0.03(0.001)$ & $<0.01$ & $1.03(1.02-1.03)$ \\
\hline \multicolumn{4}{|l|}{ Lameness } \\
\hline Absent & - & - & 1.00 \\
\hline Present & $-0.27(0.061)$ & $<0.01$ & $0.78(0.68-0.86)$ \\
\hline
\end{tabular}

${ }^{1}$ Interpretation: $50-\mathrm{kg}$ increases in BW at calving increased the daily hazard of conception post-PSM date by a factor of 1.03 (95\% CI $0.74-1.41)$. 
5492

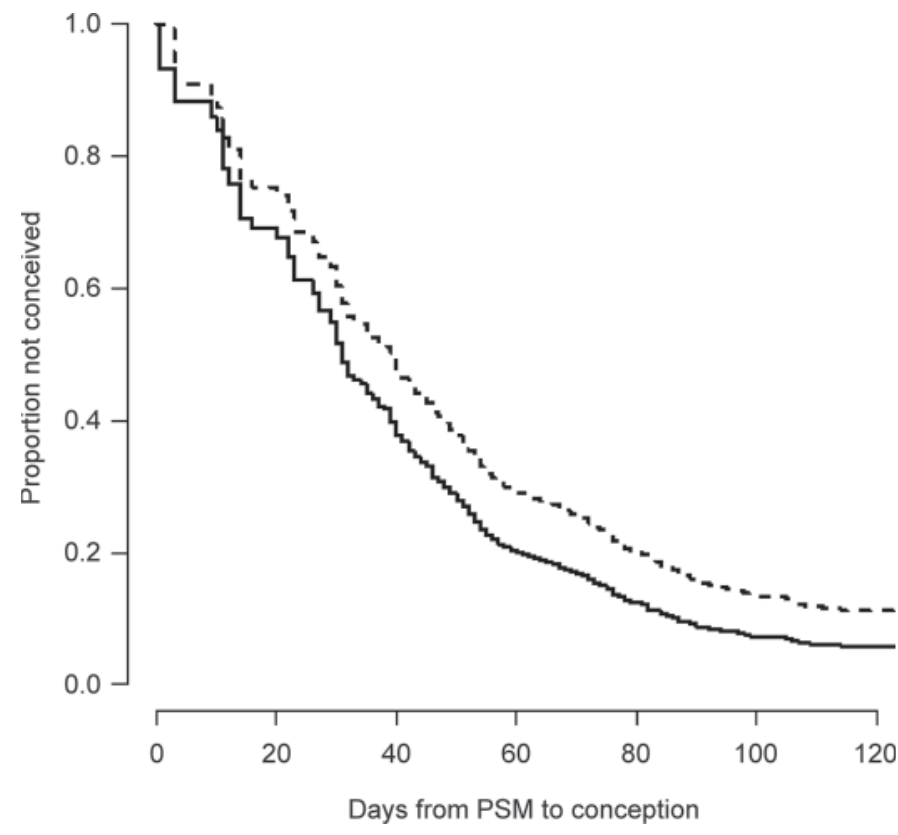

Figure 3. Covariate-adjusted survival curve, estimated from the multivariable Cox proportional hazards model, showing the cumulative proportion of cows not conceived for (1) a first-parity HolsteinFriesian cow weighing $400 \mathrm{~kg}$ that calved $50 \mathrm{~d}$ before the planned start of mating (PSM; October 24, 2008) and was not observed lame (solid line) and (2) a first-parity Holstein-Friesian cow weighing $400 \mathrm{~kg}$ that calved $50 \mathrm{~d}$ before the PSM and was observed lame during the period from calving to the PSM (dashed line).

median days from the PSM to conception was $12 \mathrm{~d}$ longer for lame cows than for non-lame ones (40 vs. 28 d). In a seasonal system, this delay can have an effect on the length of the subsequent lactation and, thus, the economic productivity of the cow (McDougall, 2010).

The current study does have limitations. First, our data were from a single herd. A herd effect likely exists on the relationship between lameness and infertility. For example, herds in which lameness is managed and identified effectively are likely to have fertility decreased less by lameness than herds in which lameness is inadequately managed. Second, this study compared lame and non-lame cows; although the cause of lameness was recorded, this was not used in the analysis. It is probable that differences exist between diseases in their effect on fertility; for example, foot rot, which is an acute infectious disease that has a short incubation period and a rapid response to treatment (Whay et al., 1998), likely has a lower effect on fertility than claw horn diseases such as white-line disease and underrun sole, which have a much longer pathogenesis and respond more slowly to treatment (Green et al., 2002; Laven et al., 2008). Additional research focusing on the effects of specific lesions on fertility is required both in housed and pasture-based cows (Huxley, 2009). Third, the treatment of all of the lame cattle in this study included separation from the main milking herd, placement in fields near the parlor, and milking once daily until the farm staff decided that they were no longer lame, to decrease distance walked. This is the standard protocol for treatment of lame cattle in New Zealand and may be one of the reasons why Laven et al. (2008) reported that the nociceptive threshold of lame cattle kept on pasture in New Zealand increased more rapidly after treatment than confined lame cattle in the United Kingdom (Whay et al., 2005).

Milking lame cows once daily may benefit the energy status of lame cows (Guinard-Flament et al., 2006), which could improve their reproductive performance, altering the apparent effect of lameness on fertility. For our assessment this is of little importance. To start with, the expected effect would be to increase the hazard of conception, which strengthens our conclusion that, in these cattle, lameness significantly decreased fertility. Second, any benefit of once daily milking on fertility is far from established; Rhodes et al. (1998a) showed that once daily milking from $7 \mathrm{~d}$ before until 21 $\mathrm{d}$ after the PSM had no effect on the interval from the PSM to conception.

\section{CONCLUSIONS}

After controlling for factors that have a significant effect on fertility (i.e., parity, breed, and calving-to-PSM interval), we found that lame cattle in pasture-based systems have a decreased risk of getting pregnant compared with their non-lame counterparts. This decreased risk of conception means that lame cows get pregnant 12 d later than non-lame cows. In seasonally calving systems where lactation length is determined by feed availability rather than date of calving, this means that the subsequent lactations of lame cows are shorter.

\section{REFERENCES}

Alawneh, J. I., N. B. Williamson, and D. Bailey. 2006. Comparison of a camera-software system and typical farm management for detecting oestrus in dairy cattle at pasture. N. Z. Vet. J. 54:73-77.

Bahonar, A. R., M. Azizzadeh, M. A. Stevenson, M. Vojgani, and M. Mahmoudi. 2009. Factors affecting days open in Holstein dairy cattle in Khorasan Razavi province, Iran; A Cox proportional hazard model. J. Anim. Vet. Advances 8:747-754.

Barkema, H. W., J. D. Westrik, K. A. S. van Keulen, Y. H. Schukken, and A. Brand. 1994. The effects of lameness on reproductive performance, milk production and culling in Dutch dairy farms. Prev. Vet. Med. 20:249-259.

Chesterton, R. N., K. E. Lawrence, and R. A. Laven. 2008. A descriptive analysis of the foot lesions identified during veterinary treatment for lameness on dairy farms in north Taranaki. N. Z. Vet. J. 56:130-138.

Clark, B. A., L. M. Chagas, P. M. Gore, B. Dow, and G. A. Verkerk. 2000. Prediction of post-partum anovulatory interval in dairy cows. Proc. N.Z. Soc. Anim. Prod. 60:15-18. 
Collick, D. W., W. R. Ward, and H. Dobson. 1989. Associations between types of lameness and fertility. Vet. Rec. 125:103-106.

Dohoo, I. R., and S. W. Martin. 1984. Disease, production and culling in Holstein-Friesian cows: IV. Effects of disease on production. Prev. Vet. Med. 2:755-770.

Dohoo, I. R., W. Martin, and W. Stryhn. 2009. Veterinary Epidemiologic Research. AVC Inc., Charlottetown, Prince Edward Island, Canada.

Ettema, J., S. Østergaard, and A. R. Kristensen. 2010. Modelling the economic impact of three lameness causing diseases using herd and cow level evidence. Prev. Vet. Med. 95:64-73.

Garbarino, E. J., J. A. Hernandez, J. K. Shearer, C. A. Risco, and W. W. Thatcher. 2004. Effect of lameness on ovarian activity in postpartum Holstein cows. J. Dairy Sci. 87:4123-4131.

Gibbs, S. J. 2010. Dairy lameness in the South Island. Pages 424-427 in Proc. Australasian Dairy Science Symposium, Lincoln University, Christchurch, New Zealand. Lincoln University, Christchurch, New Zealand.

Green, L. E., V. J. Hedges, Y. H. Schukken, R. W. Blowey, and A. J. Packington. 2002. The impact of clinical lameness on the milk yield of dairy cows. J. Dairy Sci. 85:2250-2256.

Guinard-Flament, J., E. Delamaire, S. Lemosquet, M. Boutinaud, and Y. David. 2006. Changes in mammary uptake and metabolic fate of glucose with once-daily milking and feed restriction in dairy cows. Reprod. Nutr. Dev. 46:589-598.

Hernandez, J., J. K. Shearer, and D. W. Webb. 2001. Effect of lameness on the calving-to-conception interval in dairy cows. J. Am. Vet. Med. Assoc. 218:1611-1614.

Hernandez, J. A., E. J. Garbarino, J. K. Shearer, C. A. Risco, and W. W. Thatcher. 2005. Comparison of the calving-to-conception interval in dairy cows with different degrees of lameness during the prebreeding postpartum period. J. Am. Vet. Med. Assoc. $227: 1284-1291$.

Hernandez-Mendo, O., M. A. G. von Keyserlingk, D. M. Veira, and D. M. Weary. 2007. Effects of pasture on lameness in dairy cows. J. Dairy Sci. 90:1209-1214.

Hosmer, D. W., S. Lemeshow, and S. May. 2008. Applied Survival Analysis: Regression Modeling of Time-to-Event Data. 2nd ed. Wiley-Interscience, Hoboken, NJ.

Hultgren, J., T. Manske, and C. Bergsten. 2004. Associations of sole ulcer at claw trimming with reproductive performance, udder health, milk yield, and culling in Swedish dairy cattle. Prev. Vet. Med. 62:233-251.

Huxley, J. N. 2009. Are lameness and infertility in dairy cows linked? Cattle Pract. 17:13-15.

Kleinbaum, D., and M. Klein. 2005. Survival Analysis: A Self-Learning Text. Springer, Berlin, Germany.

Laven, R. A., and C. W. Holmes. 2008. A review of the potential impact of increased use of housing on the health and welfare of dairy cattle in New Zealand. N. Z. Vet. J. 56:151-157.

Laven, R. A., K. E. Lawrence, J. F. Weston, K. R. Dowson, and K. J. Stafford. 2008. Assessment of the duration of the pain response associated with lameness in dairy cows, and the influence of treatment. N. Z. Vet. J. 56:210-217.

McDougall, S. 2010. Effects of treatment of anestrous dairy cows with gonadotropin-releasing hormone, prostaglandin, and progesterone. J. Dairy Sci. 93:1944-1959.

Melendez, P., J. Bartolome, L. F. Archbald, and A. Donovan. 2003. The association between lameness, ovarian cysts and fertility in lactating dairy cows. Theriogenology 59:927-937.

R Development Core Team. 2010. R: A Language and Environment for Statistical Computing. R Foundation for Statistical Computing, Vienna, Austria.

Rhodes, F. M., B. A. Clark, K. L. Macmillan, and S. McDougall. 1998a. Use of once daily milking compared with treatment with progesterone and oestradiol benzoate (ODB) in anoestrous cows. Proc. N.Z. Soc. Anim. Prod. 58:44-46.

Rhodes, F. M., B. A. Clark, D. P. Nation, V. K. Taufa, K. L. Macmillan, M. L. Day, A. M. Day, and S. McDougall. 1998b. Factors influencing the prevalence of postpartum anoestrus in New Zealand dairy cows. Proc. N.Z. Soc. Anim. Prod. 58:79-81.

Schwager-Suter, R., C. Stricker, D. Erdin, and N. Künzi. 2001. Quantification of changes in body weight and body condition scores during lactation by modelling individual energy balance and total net energy intake. Anim. Sci. 72:325-334.

Suriyasathaporn, W., M. Nielen, S. J. Dieleman, A. Brand, E. N. Noordhuizen-Stassen, and Y. H. Schukken. 1998. A Cox proportional-hazards model with time-dependent covariates to evaluate the relationship between body-condition score and the risks of first insemination and pregnancy in a high-producing dairy herd. Prev. Vet. Med. 37:159-172.

Szklo, M., and F. J. Nieto. 2007. Epidemiology: Beyond the Basics. 2nd ed. Jones and Bartlett, Sudbury, MS.

Therneau, T., and T. Lumley. 2009. Survival: Survival analysis, including penalised likelihood. $\mathrm{R}$ package version 2.26-2. Accessed Aug. 17, 2011. http://cran.r-project.org/web/packages/survival/ index.html.

Thiengtham, J., T. J. Parkinson, and C. W. Holmes. 2008. Postpartum follicular and luteal activity in Holstein-Friesian cows genetically selected for high or low mature bodyweight: Relationships with follicle stimulating hormone, insulin, insulin-like growth factor-1 and growth hormone. N. Z. Vet. J. 56:310-318.

Tranter, W. P., and R. S. Morris. 1991. A case study of lameness in three dairy herds. N. Z. Vet. J. 39:88-96.

Walker, S. L., R. F. Smith, J. E. Routly, D. N. Jones, M. J. Morris, and H. Dobson. 2008. Lameness, activity time-budgets, and estrus expression in dairy cattle. J. Dairy Sci. 91:4552-4559.

Whay, H. R., A. E. Waterman, A. J. F. Webster, and J. K. O'Brien. 1998. The influence of lesion type on the duration of hyperalgesia associated with hindlimb lameness in dairy cattle. Vet. J. 156:23-29.

Whay, H. R., A. J. F. Webster, and A. E. Waterman-Pearson. 2005. Role of ketoprofen in the modulation of hyperalgesia associated with lameness in dairy cattle. Vet. Rec. 157:729-733. 